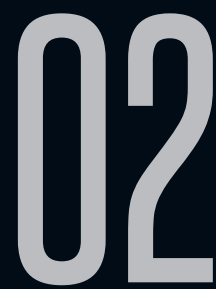

\title{
NO PAÍS DOS VAPORISTES: O CONCEITO DE "RECICLAGEM" DE GIRARDOT E MÉRESTE E 0 STEAMPUNK À FRANCESA ${ }^{1}$
}

Bruno Anselmi Matangrano (USP)

Recebido em 03 mar 2020. Bruno Anselmi Matangrano é pesquisador, editor Aprovado em 23 mar 2020.

e tradutor. Bacharel, Mestre e Doutor em Letras pela Universidade de São Paulo (USP), concentra suas pesquisas sobre as literaturas simbolista e decadentista, escritas em português e francês, assim como sobre as vertentes do insólito ficcional. É membro dos grupos de pesquisa POEM (Poéticas e Escritas da Modernidade), da USP, e "Nós do Insólito: vertentes da ficção, da teoria e da crítica", da Universidade Estadual do Rio de Janeiro (UERJ), assim como do LÉA (Lire en Europe Aujourd'hui), rede de pesquisa internacional da Universidade de Lisboa (FLUL). Além disso, é autor dos livros Contos para uma noite fria (2014) e Fantástico Brasileiro: o insólito literário do romantismo ao fantasismo (2018), com Enéias Tavares.

Resumo: Tendo como ponto de partida o artigo "O Steampunk: uma máquina literária de reciclar o passado", dos escritores-pesquisadores franceses Jean-Jacques Girardot e Fabrice Méreste, o presente ensaio procura discutir o conceito de "reciclagem" proposto pelos autores como elemento estrutural do gênero a partir de exemplos de obras

1 Título em francês: Dans le pays des vaporistes : le concept de "recyclage" de Girardot et Méreste et le Steampunk à la française. 
contemporâneas, bem como debater a própria ideia de "gênero" em contraponto à ideia de "movimento" e de "estética". Em um segundo momento, apresentase um panorama da literatura steampunk na França, mostrando o quanto essa vertente se desenvolveu nos anos subsequentes à publicação do artigo, quatorze anos atrás, atentando para o surgimento de editoras e de crítica especializada, de modo a demonstrar a importância e atualidade desse gênero-estética no contexto literário contemporâneo francês.

Palavras-chave: Steampunk; Vaporistes; Literatura Francesa; Crítica Francesa.

Résumé: Ayant comme point de départ l'article "Le Steampunk : une machine littéraire à recycler le passé», des écrivains-chercheurs français JeanJacques Girardot et Fabrice Méreste, cet essai cherche discuter le concept de "recyclage» proposé par ces auteurs en tant qu'élément structurel du genre à partir des exemples contemporains, ainsi que débattre la propre idée de "genre» en contrepoint à l'idée de "mouvement» et d'«esthétique». Dans une seconde partie, nous présentons un panorama de la littérature steampunk en France, pour montrer comme ce type de texte s'est développé dans les années qui ont suivi la publication originale de l'article il y a quatorze ans, en mettant relief sur l'apparition des maisons d'édition et d'une critique spécialisées, de façon à démontrer l'importance et l'actualité de ce genre-esthétique dans le contexte littéraire contemporain français.

Mots-clés: Steampunk; Vaporistes; Littérature Française; Critique Française. 


\section{Plano detalhado do texto: ${ }^{2}$}

\section{O conceito de reciclagem e o steampunk}

1.1. O artigo de Girardot e Méreste e a tradição francesa de FC

1.2. A reciclagem, recurso retrofuturista, ucrônico e "alternativo"

1.3. Steampunk: gênero, subgênero, movimento ou estética?

2. No país dos vaporistes: steampunk à francesa

2.1. Principais livros

2.2. Editoras e coleções especializadas

2.3. Estudos e manuais

3. Últimas considerações

\section{Bibliografia}

\section{O CONCEITO DE RECICLAGEM E O STEAMPUNK}

\subsection{O ARTIGO DE GIRARDOT E MÉRESTE E A TRADIÇÃO FRANCESA DE FC}

Publicado em 2006, na revista Cycnos, editada pela Universidade de Nice, o artigo "O steampunk: uma máquina literária de reciclar o passado", escrito por Jean-Jacques Girardot e Fabrice Méreste, faz parte de um dossiê que traz as contribuições de um colóquio ocorrido no ano anterior em torno do tema A Ficção Científica na História, a História na Fiç̧ão Científica. Sua aparição coincide, portanto, com o momento de viragem na história dessa vertente que pouco a pouco superou os limites geográficos de seu país natal

2 Uma vez que esse texto se trata de um artigo a partir de (e em diálogo com) o ensaio de Jean-Jacques Girardot e Fabrice Méreste, cuja tradução para o português também se encontra publicada neste mesmo número da revista Abusões, optei por emular o método de organização francês em plano detalhado, iniciando o texto com os tópicos a serem desenvolvidos, assim como o fizeram os dois autores em seu próprio texto. 
- os Estados Unidos da América do Norte - para ganhar espaço em outras paragens e, notadamente, em França, onde se desenvolverá rapidamente por volta dos anos 2000.

Pensar nesse movimento, do surgimento do steampunk na Califórnia dos anos 1980 à sua introdução na cena francesa do novo milênio, pode suscitar uma impressão do bom filho que à casa torna. Isso porque, mesmo se nascido nos EUA, o steampunk como bem o demonstram os dois pesquisadores, tem "ascendência" europeia, tendo como antepassados ao menos três nomes evocados por Girardot e Méreste: o inglês H. G. Wells, o belga J-H. Rosny Aîné e o francês Jules Verne, um dos mais prolíficos e populares escritores franceses do século XIX e um dos autores mais traduzidos mundo afora ao longo de todo o século XX.

Não por acaso, os franceses têm uma extensa tradição de narrativas associadas à Ficção Científica (doravante FC), de modo geral, e, mais particularmente, ao que chamam de romances de antecipação, isto é, narrativas onde são feitas previsões de futuros possíveis a partir do desenvolvimento tecnológico e de descobertas científicas, o que grosso modo se sobrepõe ao conceito de FC, mas nem sempre, uma vez que esta pode ser bem mais abrangente, englobando categorias não abarcadas por aquela, como os relatos pré-históricos, os space opera, as aventuras de viagem no tempo ou quaisquer tramas passadas no tempo presente, num passado hipotético ou em outras realidades/dimensões. Por outro lado, dada sua característica intrínseca de projeção, muitas histórias de antecipação podem também ser lidas como utopias ou como distopias. 
É na França que surgem narrativas, tornadas transmidiáticas, como: O Planeta dos Macacos (1963), de Pierre Boule, já adaptado diversas vezes para cinema, jogos eletrônicos, televisão e quadrinhos; Valérian, agente espaço-temporal, série em quadrinhos roteirizada por Pierre Christian, desenhada por Jean-Claude Mézières e colorida por Évelyne Tranlé, cujas primeiras histórias aparecem em 1967, tendo sido adaptada para o cinema pelo também francês Luc Besson em 2017; ou ainda a trilogia das formigas e outros títulos do best-seller Bernard Werber, já traduzidos para inúmeros idiomas.

É curioso, portanto, que tenha demorado tanto para surgir um steampunk legitimamente francês, apesar dessa longa tradição, do fato de Paris ser um constante cenário de narrativas steampunk e de Jules Verne ser considerado uma das principais referências do gênero, sendo inclusive uma das figuras históricas mais constantemente recriada. Em 2006, a expansão do gênero apenas começava a ser vislumbrada; felizmente, hoje em dia, o steampunk já é uma vertente consolidada das chamadas "literaturas do imaginário"3 francesas.

No Brasil, no entanto, onde o steampunk também se proliferou muito e rapidamente ao longo das duas décadas do século XXI

3 Os estudos acadêmicos e o mercado editorial franceses usam essa expressão (no original, littératures de l'imaginaire ou, às vezes, simplesmente, l'imaginaire) como conceito "guarda-chuva" abrangente, para se referir às diversas vertentes do que no Brasil chamamos de "insólito ficcional", equivalendo ou aproximando-se, portanto, dos conceitos da tradição anglófona de "literatura fantástica" (vista em seu sentido lato) ou "ficção especulativa".

4 Vários trabalhos têm se ocupado em mapear as produções steampunk brasileiras, notadamente, na literatura. Recomenda-se, sobretudo, a ótima dissertação de mestrado de Jayme Soares Chaves (2015), intitulada Viagens Extraordinárias e ucronias ficcionais: uma possível arqueologia do steampunk na literatura. Rio de Janeiro: UERJ (Dissertação - Mestrado). A esse respeito, também publiquei o breve artigo de divulgação "A Hora do steampunk" (MATANGRANO, 2016a), que, por sua vez, serviu de base ao capítulo "Viagem a um passado futurista: o steampunk" do livro Fantástico Brasileiro: o insólito 
pouco se fala da literatura steampunk de língua francesa, ou mesmo da tradição francófona de romances de FC ou de antecipação para além de Jules Verne; tampouco é comentada a crítica desenvolvida na França em torno dessa estética nascida nos Estados Unidos.

Nesse contexto, a publicação em português do texto de Girardot e Méreste revela sua importância, uma vez que o ensaio não apenas apresenta uma importante teoria de análise de textos steampunk com a sistematização do conceito de "reciclagem", como também traça as raízes francófonas do gênero, bem como introduz brevemente a literatura steampunk francesa feita na primeira década do novo milênio, quando comenta duas das primeiras antologias steampunk publicadas na França: Futurs antérieurs, 15 récits de littérature steampunk [Futuros anteriores, 15 narrativas de literatura steampunk], organizada por Daniel Riche em 1999, e Passés Recomposés (anthologie uchronique) [Passados recompostos - Antologia ucrônica], dirigida por André-François Ruaud em 2003, na qual figura a novela "Quand s'envoleront ma vie et ma conscience..." [Quando minha vida e minha consciência ascenderem...], assinada pelos próprios Girardot e Méreste e brevemente autoanalisada ao fim de seu ensaio.

literário do romantismo ao fantasismo (2018), que escrevi com Enéias Tavares. No que diz respeito às HQs steampunk brasileiras, até onde se pode pesquisar, não foi feito ainda um levantamento e estudo sistemático; contudo, nota-se nesse sentido uma expressiva participação da editora AVEC em sua difusão nos últimos quatro anos, de cujo catálogo destacamos os títulos: Salto (2017) e Silas (2019), de Rapha Pinheiro (arte e roteiro); Desafiadores do Destino: Disputa por controle (2018), de Felipe Castilho (roteiro) e Mauro Fodra (arte); Le Chevalier: arquivos secretos (2017) e Le Chevalier nas Montanhas da Loucura (2018), ambos de A. Z. Cordenonsi (roteiro) e Fred Rubim (arte). Vale ainda citar Steampunk Ladies: Vingança a vapor (2017), de Zé Wellington (roteiro) e Di Amorim (arte), publicada pela Draco, editora que, assim como a AVEC, também já lançou vários romances e antologias steampunk. Por outro lado, ao contrário do visto em relação às publicações de literatura e de quadrinhos, o Brasil ainda não possui um cenário consolidado de narrativas audiovisuais steampunk. 
Curiosamente, a despeito da falta de publicações ou comentários sobre o steampunk francófono nos nascentes estudos brasileiros em torno de narrativas steampunk, o artigo de Girardot e Méreste é constantemente citado em estudos acadêmicos ${ }^{5}$, mostrando o impacto e a relevância de sua teoria da reciclagem, bem como a importância de se o traduzir, facultando assim o acesso a mais pesquisadores, que eventualmente não o consigam ler em seu idioma original.

Diante dessa breve introdução, pretende-se neste ensaio também um diálogo com os dois pesquisadores-escritores e uma apresentação do steampunk francófono à audiência brasileira -, discutir as propostas desenvolvidas por Girardot e Méreste, bem como mostrar um pouco o que vem sido produzido na língua de Molière em termos de narrativas retrofuturistas nos quase quinze anos que se sucedem à publicação de "O steampunk: uma máquina literária de reciclar o passado".

\subsection{A RECICLAGEM, RECURSO RETROFUTURISTA, UCRÔNICO E "ALTERNATIVO"}

O eixo em torno do qual se constrói o processo argumentativo do artigo de Girardot e Méreste é o conceito de reciclagem, identificado por eles, por sua vez, como o procedimento estruturador das narrativas steampunk por excelência. Para eles, essa reciclagem

5 Dentre os estudos brasileiros que citam o texto de Girardot e Méreste até o momento da publicação desse artigo podemos mencionar: "Um personagem, dois mundos: Isaías Caminha em 1909 e em 2014" (CALEGARI; AMARAL-OLIVEIRA, 2018); "Ficção científica retrofuturista e fantasismo brasileiro", (CHAVES, 2019); "Polifonia retrofuturista: a (re)criação de vozes literárias na série Brasiliana Steampunk" (TAVARES, 2017), bem como o meu artigo "O olhar contemporâneo na releitura do moderno. A lição de anatomia do temível Dr. Louison" (MATANGRANO, 2016b) e o livro Fantástico Brasileiro (MATANGRANO, TAVARES, 2018). 
pode se dar de várias formas e em vários níveis. A mais óbvia é a recriação de personagens e a revisitação de tramas, seja a partir de pessoas e fatos históricos, seja a partir de personagens e cenários presentes em obras ficcionais anteriores. Como exemplo, citam o romance Morlock Night (1979), de K. W. Jeter, um dos textos fundadores do gênero, apresentado como possível sequência do romance A Máquina do Tempo, de H. G. Wells; citam também a novela "Quand s'envoleront ma vie et ma conscience...", assinada pela própria dupla, na qual, em uma Paris retrofuturista, diversas figuras históricas vivem aventuras "rocambolescas".

Nesse sentido, poderíamos acrescentar vários outros títulos a essa lista, como A Liga Extraordinária, novela gráfica roteirizada por Alan Moore, cuja primeira publicação se deu em 1999. Nesta que é uma das mais célebres e elogiadas HQs steampunk, vemos um grupo de heróis e vilões oriundos de obras vitorianas reunidos para combater um super-vilão folhetinesco. A partir dessa obra, torna-se muito frequente esse tipo de narrativa steampunk na qual personagens provenientes de várias outras são reunidos em novas histórias, como na trilogia de quadrinhos Império, de Igor Kordey (arte) e Jean-Pierre Pécau (roteiro). Nas palavras de Étienne Barillier e Arthur Morgan, em seu Guide Steampunk, em Império:

A série multiplica as piscadas de olho, assumindo sua herança ucrônica: figuras histórias abundam, Mary Shelley, Charles Babbage, as invenções da época são sutilmente alteradas - da eletricidade aos autômatos até a aparição das primeiras máquinas funcionando a "óleo de rocha". As alusões literárias são múltiplas, Drácula, Frankenstein, a Rua Morgue, O Livro da Selva. (2013, p.189 - tradução nossa) 
No Brasil, diversas obras se valem desse recurso, como o romance Homens e Monstros: A Guerra Fria Vitoriana (Ed. Draco, 2013), do brasileiro Flavio Medeiros, no qual "os acontecimentos políticos e econômicos do século XIX se deram de forma bem diferente: com o Império Britânico dominando as ex-colônias espanholas enquanto os franceses também expandem seus domínios, fazendo o mundo ficar polarizado numa Guerra Fria avant la lettre" (MATANGRANO, TAVARES, 2018, p.195). Ou ainda, A Lição de Anatomia do Temível Dr. Louison, de Enéias Tavares, no qual, aos moldes de A Liga Extraordinária, mas de uma forma muito brasileira, o autor revisita diversas obras da literatura nacional do século XIX, formando um grupo de sábios e artistas anarquistas que enfrentam o obscurantismo de um grupo rival.

No entanto, algumas questões podem ser levantadas a partir disso. A primeira é relativa a outras formas narrativas que também se estruturam por revisitação de livros literárias e de fatos históricos e que, portanto, a rigor também se valeriam do conceito de reciclagem de personagens e cenários, defendido e elaborado por Girardot e Méreste, como é o caso das chamadas História Alternativa e Ficção Alternativa, que, na França, são mais conhecidas sob a etiqueta ucronia, caso da série televisiva Penny Dreadful (2014-2016) ${ }^{6}$, por exemplo, e dos romances Anno Dracula (1998), de Kim Newman, e suas sequências. A segunda dúvida diz respeito a obras inequivocamente steampunk que não se valem desse recurso, como é o caso das obras steamfantasy ${ }^{7}$, passadas 6 A respeito dessa série e de seus aspectos "reciclados", ver TAVARES; MATANGRANO, 2016 e 2018.

7 Steamfantasy é uma subcategoria do steampunk que aplica sua estética a mundos de fantasia. Trata-se de uma vertente bastante recente que, apesar de bastante popular na segunda década do século XXI nas mais variadas mídias, ainda carece de maiores estudos. 
em mundos secundários, como A Corte do Ar (2007) e O Reino mais além das ondas (2008), e demais volumes da série de Stephen Hunt, mas também de obras passadas no nosso mundo nas quais todas as personagens são originais, como O Peculiar (2012) e Não-sei-quê (2013), de Stefan Bachmann, ou ainda Guanabara Real: a alcova da morte (2017), de Enéias Tavares, Nikelen Witter e A. Z. Cordenonsi. Ou seja, se essa é uma característica intrínseca ao gênero, como explicar, de um lado, obras que não a usam, mas continuam sendo steampunks, e, de outro, narrativas que a usam, mas não o são?

A resposta reside no fato de que a reciclagem, para os dois escritores-pesquisadores, não é apenas de personagens e enredos - não é a simples reutilização de personagens literárias e históricas já existentes -, mas igualmente a reutilização de métodos, procedimentos, elementos textuais, cenários, de modo a criar algo novo, moderno, e, ao mesmo tempo, transparecer, pela incorporação e pela intertextualidade, a atmosfera tipicamente oitocentista. Enfim, a essência da narrativa steampunk, portanto, seria a reciclagem em vários níveis, como o explicitam em cada um dos tópicos de seu artigo ${ }^{8}$.

Nesse sentido, os steamers (como são conhecidos os autores de narrativas steampunk) buscariam sua "matéria-prima" em obras de contexto variado: da FC, do "romance científico" e do "maravilhoso científico"9 buscariam os recursos tecnológicos de então, seus métodos e procedimentos; dos folhetins, buscariam o tom 8 Além disso, é necessário ter-se em conta que o steampunk, como qualquer outra modalidade literária, está em crescente transformação, de modo que novos procedimentos vão tomando lugar de outros e opções estéticas diferentes e novas acabam por surgir de tempos em tempos, como recentes narrativas distópicas steampunk, caso de O Circo Mecânico Tresaulti, de Genevieve Valentine (2011).

9 Gênero tipicamente francês que antecede o surgimento da Ficção Científica, circunscrito ao período aproximado de 1900 e 1930. 
aventuresco e a trama rocambolesca, estruturada nos princípios aristotélicos de peripécia e reconhecimento; do maravilhoso e da nascente fantasia reciclariam os elementos mágico-sobrenaturais, o misticismo ocultista, os mundos secundários e os portais entre mundos e realidades; e assim por diante, valendo-se desse procedimento também com fatos históricos.

Contudo, frente a essa resposta, ainda outra questão pode ser levantada relativa à possível diferença (ou semelhança) entre a reciclagem como procedimento estético e outras formas de recriação literária já canônicas por meio da intertextualidade, como o pastiche e a paródia, ou mesmo o recente fenômeno das fanfictions (também chamadas fanfics ou "ficções de fã"). Para tanto, convém definir brevemente cada um desses três recursos.

O pastiche se define por duas características: primeiro, pela tentativa de um autor em recriar o estilo autoral de outro; segundo, por se compor como colagem, trazendo traços, elementos e até mesmo trechos de outras obras, aproximando-se assim da montagem (MOISÉS, 2004, p.342). A paródia, por outro lado, partindo de um texto base que ela altera em algum nível, mas mantém reconhecível o bastante para deixar escancarada a relação, busca sempre a criação de um efeito cômico, e/ou satírico, mesmo se não deixa de ser uma homenagem ${ }^{10}$; trata-se de recurso essencialmente metalinguístico e típico da literatura moderna (cf. SANT'ANNA, 2007, p.7). Por fim, a fanfic é simplesmente uma história original criada por um fã a partir de uma narrativa de que 
ele gosta, difundida, geralmente, pela internet; diferenciar-se-ia, assim, de outras práticas de recriação pelo fato de não "possuírem preocupações estéticas ou literárias", sendo antes uma atividade recreativa. "Isso posiciona as fanfics num contexto cultural muito mais amplo, com a atuação direta dos fãs nos produtos da cultura pop" (LUIZ, 2008, p.1-2.) $)^{11}$.

Com essas definições sumárias em mente, torna-se possível perceber que o steampunk, enquanto categoria narrativa, pode se aproximar de tais recursos, por vezes valendo-se de alguns de seus elementos, mas isso nem sempre ocorre. Nesse sentido, os próprios Girardot e Méreste destacam a relação entre o gênero e o pastiche, frequentemente a ele associado:

Quanto ao steampunk, tudo começou, dizem, por uma simples brincadeira: ao fim dos anos 1970, três autores californianos decidiram zombar do cyberpunk nascente restituindo a ficção científica sob forma de pastiche às suas origens, o famoso "romance científico" escrito por autores como $\mathrm{H}$. G. Wells, na Londres da época vitoriana. (2020, p.329 - grifos nossos)

11 Como lembra o pesquisador Lucio Luiz no artigo já citado, a ideia de reescrever ou continuar uma história de que se gosta não é novidade da época contemporânea, remontando a Antiguidade e o período medieval. Podemos pensar, por exemplo, na Eneida, de Virgílio, enquanto continuação da Ilíada, de Homero, e em As Aventuras de Telêmaco, de Fénelon, apresentada como sequência da Odisseia também homérica. Mais do que uma prática, a literatura clássica e classicista prezava a característica da "emulação". Segundo esse pensamento, a qualidade não estaria em sua inventividade narrativa, mas na capacidade de cada autor em contar, à sua maneira, uma história já conhecida. A prática teria diminuído em um primeiro momento, com o advento da ideia de originalidade, no período romântico. Luiz lembra ainda que com as leis de direito autoral, surgiram restrições legais para o uso de personagens, nomes, cenários e conceitos criados por terceiros, motivo pelo qual a fanfic se difunde, sobretudo, na internet em comunidades e blogs, justificadas por não terem fins lucrativos e toleradas, em geral, pelos detentores dos direitos, pois ajudam a divulgar a obra original e fortalecem a base de fãs (cf. LUIZ, 2008, p.2). 
Portanto, o steampunk volta-se ao pastiche, quando se compõe como uma colagem de diversos textos e referências, ou quando tenta imitar o estilo de um autor, o que faz, por exemplo, Enéias Tavares em alguns momentos de A Lição de Anatomia do Temível Dr. Louison ao emular a escrita de Machado de Assis para recriar a voz de Simão Bacamarte, protagonista de $O$ Alienista $^{12}$. O steampunk torna-se paródia, por sua vez, quando necessariamente busca criar humor ou satirizar a obra original que revisita, o que parece bem mais raro, embora não impossível. Por outro lado, um romance, um filme ou uma HQ steampunk não se tornam fanfic por pressuporem pretensão artístico-literária bem como por terem objetivos de mercado (isto é, mesmo sendo manifestações artísticas, também são um produto concebido como tal), o que não impede, porém, a existência de fanfics de e em universos steampunk ou fanfics que releiam alguma história a partir de uma perspectiva e/ou estética desse gênero.

Em suma, o steampunk não precisa apresentar nenhum desses três recursos criativos, embora possa se valer deles ou flertar com eles em contextos específicos. Por outro lado, conforme demonstrado aqui e detalhado no artigo de Girardot e Méreste, esse tipo de narrativa sempre recorrerá a alguma forma de "reciclagem", isto é, a reelaboração a partir de elementos préconcebidos, reelaborados pelo viés estético do steampunk.

12 Analisei essa questão no artigo "O Olhar Contemporâneo na releitura do moderno: A Lição de Anatomia do Temível Dr. Louison" (MATANGRANO, 2016b, p.267 e ss.), onde contrastei trechos do livro de Tavares e do livro de Machado para mostrar semelhanças e discrepâncias na construção das duas versões de Simão Bacamarte. 


\subsection{STEAMPUNK: GÊNERO, SUBGÊNERO, MOVIMENTO OU ESTÉTICA?}

Uma das dificuldades da definição de steampunk, como pode ser visto pelas próprias argumentações acima, é a dificuldade de se definir sua categoria. Nascido como subgênero da FC, logo foi apresentado como gênero autônomo ou mesmo movimento e, por ter extrapolado os limites midiáticos com os quais foi concebido em pouco tempo se tornou uma estética. Essa fluidez epistemológica, que tanto diz respeito à visão diacrônica do conceito quanto ao seu potencial de hibridização e de adaptação a diferentes plataformas, mídias e meios, no entanto, não é facilmente entendida ou percebida, gerando equívocos e confusões, merecendo, portanto, alguma reflexão.

Como narrado por Girardot e Méreste, o termo nasce de um projeto autoral de três autores, J. W. Jeter, Tim Powers e James Blaylock, que o propõem ao editor da revista Locus como forma de se entender e de aproximar os romances que os três vinham criando no fim dos anos 1970 e começo dos anos 1980. Tratavase, segundo as palavras de Jeter, de "fantasias vitorianas" escritas em um estilo "pseudo-histórico". O trio propõe então o conceito de steampunk para definir esses livros, por associação ao conceito já pré-existente de cyberpunk. Ou seja, em um primeiro momento, eles o entendem como uma categoria aparentada a esta última, já vista como subgênero dentro do espectro do conceito abrangente de FC. Há quem identifique aí um "movimento" já nascente, mas tal alcunha parece um tanto deslocada nesse momento inicial, uma vez que mais do que uma categoria essencialmente estética, o conceito de movimento pressupõe uma ideologia, uma consciência de grupo e de classe, bem como ações conjuntas, eventos, 
publicações, debates, uma forma de se contrapor a uma corrente então vigente. Não parece ser o caso do steampunk, proposto antes (e inicialmente) como uma variação extrapolada e criativa de um conceito já existente, o cyberpunk, e circunscrito aos seus três criadores a princípio. Além disso, os movimentos nem sempre têm uma única e coesa estética - vide o Modernismo, composto por diversas estéticas diferentes unidas apenas pela ideia de ruptura com a tradição e inovação - enquanto o steampunk desde o começo, apesar de sua multiplicidade, tem em sua estética sua coesão.

O fato de o conceito ter rapidamente se espalhado e se difundido, contudo, aponta seu potencial para se configurar em movimento, embora essa não pareça ter sido uma preocupação dos steamers de antes ou de depois. Por outro lado, o steampunk logo ganhou ares de estética, à medida que deixou de se tornar uma categoria narrativa (como um gênero ou subgênero ou modo) para se tornar uma questão de visual, de ambientação e de cenário.

O fato de um livro ou de um filme ser steampunk não pressupõe uma forma de se contar uma história, mas pressupõe como e com o que o mundo no qual ela se passa vai se parecer. Mais do que isso, o steampunk deixou de se restringir a artes narrativas, como a literatura (onde surgiu), o cinema e as HQs (mídias onde rapidamente se proliferou $\left.{ }^{13}\right)$, para se tornar também uma categoria de moda, decoração e artesanato, norteada pelos mesmos princípios estéticos. Nesse sentido, tanto se pode classificar uma roupa ou filme quanto uma história ou uma cadeira como sendo feitos segundo a estética

13 A respeito da sétima arte de viés steampunk ver o livro Steampunk Cinema: un repaso a las 25 mejores películas steampunk de la historia (ARGÜELLES, 2013), no qual é feito um extenso levantamento das produções cinematográficas associadas ao gênero nos últimos anos. 
steampunk. Esse fenômeno se deu de tal modo que o termo se tornou, e adquiriu também, um código de vestimenta pelo qual é agora possível identificar seus adeptos: ou seja, o steampunk - tal como o gótico ou o punk - também se tornou uma "tribo" urbana, que não necessariamente consome as narrativas que lhe deram origem, mas na qual está pressuposta a adequação visual ${ }^{14}$.

Esse deslocamento de paradigma, de uma categoria narrativa para uma categoria visual e/ou estética, tornou ainda possível a criação de obras que, sem serem steampunk (por não trazerem uma ambientação vitoriana ou belle époque, por não terem proposta retrofuturista ou por não se valerem do tão debatido princípio da reciclagem), ainda assim, são constantemente associadas a ele.

Nesse sentido, poderiam ser lidos como obras de estética steampunk, mas não necessariamente de um gênero ou modo narrativo steampunk, por exemplo: o romance (e sua adaptação para o cinema dirigida por Martin Scorcese) A invenção de Hugo Cabret (2007) de Brian Selznick; o livro Coraline (2002) de Neil Gaiman (e sua adaptação em animação dirigida por Henry Selick); os filmes e HQs do universo da personagem Hellboy, notadamente, o segundo filme dirigido por Guillermo del Toro em 2008; o livro A Mecânica do Coração (2007), do francês Mathias Malzieu, também responsável pela adaptação em animação (e pelos vídeo-clips de sua banda Dionysos inspirados na trama) etc. Em todas essas obras, o elemento steampunk é um detalhe, em maior ou menor grau. Pode ser a presença de um autômato (como

14 Sobre o steampunk como fenômeno social estético e urbano, bem como sua relação com as artes concebidas dentro desses mesmos valores estéticos, ver PEGORARO, 2012a, 2012b, 2014 e 2015. Ainda nesse sentido, recomenda-se a dissertação de mestrado de Joana Costa (2013), na qual, além de ter analisado numerosas obras literárias, também se comenta o steampunk na moda, no artesanato e na música, trazendo um curioso estudo de caso sobre a "Sociedade Steampunk", de Glasgow, na Escócia. 
no livro de Selznick), o uso de gadgets típicos (como os óculos usados em Hellboy 2, no qual há também uma personagem cujo espírito vive num corpo mecânico), ou ainda a ideia de fundir corpos humanos a máquinas movidas a vapor e/ou a corda, tendo a engrenagem como símbolo de seu caráter steampunk (vide a personagem Jack e seu coração de relógio no livro de Malzieu).

Em suma, o steampunk pode ser tudo isso, a um só tempo, um gênero (ou modo ou subgênero narrativo), uma estética, quiçá um movimento ou mesmo um fenômeno social; ele ultrapassou bastante os limites com os quais foi concebido, e entendê-lo epistemologicamente como uma ou outra categoria vai depender de quais elementos estão sendo analisados e, consequentemente, esse recorte acabará por guiar a leitura e a interpretação. E, por conta dessa distinção, nem sempre uma obra esteticamente associada ao steampunk o será também modal e genericamente; mas o estético sempre estará implícito no gênero, motivo pelo qual, em muitos contextos, parece menos problemático entendê-lo simplesmente como uma categoria estética e/ou visual.

\section{NO PAÍS DOS VAPORISTES: O ATUAL STEAMPUNK À FRANCESA}

\subsection{PRINCIPAIS LIVROS ${ }^{15}$}

Entendido como o steampunk se configura e se estrutura, passemos ao contexto francês propriamente dito, através de seus

15 Essa seção sumariza a listagem e as resenhas apresentadas nos capítulos dedicados à produção literária francófona steampunk dos livros Le Guide Steampunk (BARILLIER; MORGAN, 2013) e Tout le Steampunk! (BARILLIER; COLSON, 2014), bem como retoma outros textos críticos como o trabalho de Riel (2015). A esse apanhado somam-se minhas próprias impressões dos romances mencionados. Dado o extenso volume de publicações, não me dediquei aqui às histórias em quadrinhos, ou a outras manifestações steampunk produzidas em França. Para tanto, ver os estudos mencionados. 
principais autores e obras, mas também, em um segundo e terceiro momentos, das casas editoriais que a ele vêm se dedicando, bem como à forma como vem sido recebido criticamente.

Para começar, convém dizer que, se os autores ou os adeptos da estética steampunk ficaram conhecidos como steamers nos países anglófonos, na França, autonomearam-se vaporistes, ou, em bom português, "vaporistas". Como foi dito aqui e identificado por Girardot e Méreste, até o início dos anos 2000, a produção francófona ainda era muito pequena, mas mesmo naquele contexto alguns nomes já despontavam, dentre os quais: Mathieu Gaborit, Fabrice Colin, Sabrina Calvo e Hervé Jubert.

O primeiro, visto como um dos pais do steampunk francês, lança em 1997, pela editora Mnémos, sua duologia Bohème, com os volumes Les Rives d'Antipolie e Revolutsyia. Passadas no mesmo mundo de Écryme (1994), um RPG criado por Gaborit em parceria com Guillaume Vincent, falecido pouco depois, as aventuras de Bohème se dão numa Europa oriental alternativa, controlada por um regime ditatorial conhecido como "a Propaganda". Esse órgão estatal detém o controle do "Écryme", uma "substância corrosiva que recobre o mundo", segundo definição do próprio Gaborit, e "incarna uma natureza desaparecida", sintetizando "o imaginário. Como uma espécie de lama primordial das emoções humanas". Com ela os criadores do universo esperavam "interrogar essa fratura entre o homem e a natureza" (GABORIT Apud BARILLIER; MORGAN, 2013, p.147 - tradução nossa).

No mesmo ano, Sabrina Calvo (então assinando como David Calvo) publica Délius, une chanson d'été, livro que dialoga 
fortemente com a vida e a obra de Sir Arthur Conan Doyle. Em 2003, Calvo publica uma continuação: La nuit des labyrinthes. No ano seguinte, Fabrice Colin publica sua duologia Arcadia (1998), dividida nos tomos Vestiges d'Arcadia e La Musique du sommeil pela Menémos, e, depois, relançados em volume único pela Bragelonne em 2014. Nessas obras, Colin cria um universo onde a humanidade está em declínio, habitado pelos pré-rafaelistas, sociedade histórica de artistas e escritores ingleses da primeira metade do século XIX, que muito influenciaria os poetas e pintores simbolistas franceses do fim do século.

Naquele mesmo ano, Hervé Jubert, lança Le Roi sans visage, no qual recria uma Paris feérica povoada por demônios e dragões, mas também por máquinas. Nas palavras de Barillier e Colson, a "ambientação steampunk", criada por Jubert, "é deliciosa", onde "figuras históricas e criaturas imaginárias se cruzam alegremente" (2014, p.148). La Fête électrique, outra narrativa steampunk, sai em 1999. Jubert voltará ao tema em outros livros, como Magies Secrètes (2012), primeiro volume da trilogia Beauregard.

Pode-se citar ainda os próprios Jean-Jacques Girardot e Fabrice Méreste, que publicam, dentre outros trabalhos, a já mencionada novela "Quand s'envoleront ma vie et ma conscience...", na coletânea Futurs antérieurs, 15 récits de littérature steampunk, organizada por Daniel Riche em 1999, melhor comentada pelos próprios autores em seu artigo. Curiosamente, Girardot e Méreste não citam nenhum dos romances publicados nessa época e nos primeiros anos do século XXI em seu texto, uma ausência que não passa despercebida. 
Ainda naquele ano e também pela Ed. Mnémos, Colin e Gaborit lançam juntos Confessions d'un automate mangeur d'opium ${ }^{16}$, cujo título se inspira explicitamente em Confissões de um inglês comedor de ópio (1822), do escritor inglês Thomas de Quincey (1785-1859), texto autobiográfico sobre a influência da droga em sua vida. Colin e Gaborit também criam uma trama cujo eixo central é a existência de uma droga misteriosa conhecida como "éter", usada como fonte de energia e até mesmo como arma.

Também em 1999, a editora Fleuve Noir lança um romance pretensiosamente anunciado como "o primeiro grande romance steampunk escrito por um francês". Trata-se de L'Équilibre des paradoxes, de Michel Pagel, definido nos seguintes termos por Étienne Barillier e Raphaël Colson:

Este livro é constituído por uma coleção de diários, cartas particulares, registros de áudio e memórias que contam de maneira fragmentária uma mesma história. O autor se apresenta como o receptário destes documentos, tendo recebido a tarefa delicada de fazer destas múltiplas vozes um todo coerente. Aí está, talvez, a primeira conquista do texto, puramente formal: a constituição de um conjunto polifônico que nos dá o saboroso prazer de frequentar de perto personagens que sofrem múltiplos choques de cultura. (2014, p.149 tradução nossa)

A obra de Pagel parece dialogar, portanto, com a forma do romance Drácula, de Bram Stocker, intensificando, porém, o caráter fragmentário e não-linear da narrativa. Estrutura semelhante foi escolhida por Enéias Tavares em $A$ Lição de 16 Infelizmente, nenhuma dessas obras - ou das outras sobre as quais falarei neste tópico - possui tradução para o português brasileiro. 
Anatomia do Temível Dr. Louison, igualmente constituído por registros variados (diários, cartas, registros de áudio), de modo a compor um todo coeso, mesmo se também fragmentário e nãolinear. Essa semelhança curiosa demonstra um dos vários pontos de contato entre o steampunk produzido em França e no Brasil, tema ainda por ser explorado, em suas tentativas paralelas de, ao mesmo tempo, enquadrarem-se na estética tal como concebida e de fugirem do jugo e da pressão do modelo instaurado pelos autores anglófonos. Esta convergência se revela interessante em particular por ter se dado mesmo se sem qualquer contato entre os dois grupos, sobretudo pelo fato de não haverem ainda traduções dos vaporistes no Brasil ou dos steamers brasileiros em França, como se a desvelar um Zeitgeist transcontinental.

Os anos 2000 começam, portanto, com grande expectativa e logo muitos romances e antologias steampunk passam a serem publicados, seja por editoras independentes voltadas exclusivamente ao imaginário, como Mnémos, seja por grandes casas editoriais como Le Livre de Poche e J'ai Lu. Johan Heliot inaugura o novo milênio com o primeiro livro de sua trilogia da lua, cujos volumes se intitulam: La Lune seule le sait (2000), La Lune n'est pas pour nous (2004) e La Lune vous salue bien (2007). Passada na exposição universal de 1899, em Paris, a trilogia recria diversas personalidades históricas, como Victor Hugo e Jules Verne, em uma trama que homenageia o autor de Da Terra à Lua. Por sua vez, Pierre Pevel, um dos mais célebres autores franceses de fantasia e ficção científica, lança em 2003 Les Enchantements d'Ambremer, que também possui uma continuação, publicada em 2004: L'Élixir d'oubli, ambas passadas na Paris belle époque reconstruída em meio à magia. Afinal, como aponta Berrilier 
e Colson, "o steampunk francês se nutre mais da Belle Époque do que de um século XIX vitoriano", pois "é preciso confessar que o nascente século XX é um terreno muito mais interessante do que o século XIX que acaba por investir o steampunk de uma identidade francófona" (2014, p.150 - tradução nossa).

Mesmo assim, além de Paris, houve muitos autores que prefeririam recriar a Londres vitoriana e, mais especificamente, aquela onde habita o célebre detetive criado por Sir Arthur Conan Doyle, como já visto a propósito de Sabrina Calvo, e como também acontece no caso de Thomas Day com seu L'Instinct de l'Équarrisseur (2003). Por sua vez, Xavier Mauméjean criou, de certa forma, sua própria versão da célebre HQ de Alan Moore - que, diga-se de passagem, também revisita Doyle, dentre outros autores - com o romance La Ligue des héros, publicado em 2002, cuja sequência, L'Ėre du dragon veio a lume em 2003 (posteriormente relançados em um único volume intitulado Le Cycle de Kraven).

Nesta duologia passada em 1898, o brincalhão Peter Pan, criação original de James Barrie (1860-1937), foge da Terra do Nunca, onde nunca cresceu, tornando-se um grande vilão na Londres vitoriana, aliando-se a toda sorte de criminosos no simples intuito de semear confusão. O governo então decide criar uma equipe de pessoas super-habilidosas para enfrentá-los, dentre os quais, Tarzan, criação de Edgar Rice Burroughs (1875-1950) e, claro, o "Mestre dos Detetives", ou seja, Sherlock Holmes, aos quais se juntam vários outros personagens vitorianos históricos e fictícios em uma trama bastante folhetinesca. Devido a estas características, Sabrina Riel analisa a obra de Mauméjean sob o prisma do conceito de reciclagem próprio do steampunk conforme postulado por 
Girardot e Méreste, bem como pelo conceito de "reciclagem cultural", proposto por Walter Moser, demonstrando, como se lê a seguir, de que maneira esse procedimento vai além da simples remissão a elementos pré-existentes para revelar uma proposta de recriação autoral e original:

Assim, o sistema referencial empregado no Ciclo de Kraven repousa sobre a reciclagem constante e exacerbada de elementos do passado histórico e cultural. Essas referências não são apenas piscadas de olhos aos leitores; elas estruturam toda a diegese na medida em que os empréstimos e reciclagens dizem respeito tanto aos personagens principais quanto às peripécias. Os elementos reutilizados no seio do ciclo narrativo de Mauméjean se revestem com muita frequência de um sentido novo, em razão da transformação que o autor os faz enfrentar, ou ainda em sua inscrição em um novo contexto. Assim o tratamento ao qual estes empréstimos estão submetidos cria um contraste, em diversos graus, com seu primeiro uso, engajando com isso o leitor a ser atento às nuances referenciais. (RIEL, 2015, p.3 - tradução nossa)

Vê-se, pois, que até aqui as obras publicadas nos primeiros anos do século $X X I$ se pautam praticamente de forma exclusiva no conceito de reciclagem, conforme teorizado pelos dois pesquisadores. A partir de 2004, aproximadamente, nota-se um ponto de viragem com um intenso aumento e diversificação de publicações, ou seja, pouco antes da publicação do artigo de Girardot e Méreste. Deste ponto em diante, a quantidade de lançamentos se multiplica e torna-se difícil mapear em poucas 
páginas toda a produção steampunk publicada em França ${ }^{17}$ nos catorze anos que nos separam da publicação do artigo; todavia, destacamos, dentre os títulos mais recentes, a duologia Pax Germanica, iniciada em 2014, de Nicolas Le Breton, passada em um mundo onde o automóvel nunca foi inventado e dirigíveis, balões e aerostatos se difundiram como principais meios de transporte. Nesse cenário, habitam personagens originais e recriações da Europa belle époque como o controverso místico Aleister Crowley e a pesquisadora laureada com o Nobel Marie Curie. Vale mencionar ainda La France steampunk (2015), dos pesquisadores Étienne Barillier e Arthur Morgan que também co-assinam Le Guide Steampunk e os novíssimos livros de Victor Fleury L'Empire Électrique (2017) e L'Homme Électrique (2019), passados em um universo de história alternativa dominado por um império napoleônico.

Nota-se, pois, a partir desse breve levantamento uma predominância por narrativas vitorianas e/ou ambientadas na belle époque novecentista de História e/ou Ficção Alternativa steampunk, com elevado número de referências. O steampunk francês parece, portanto, muito mais interessado em recriar o seu passado do que inventar novos mundos sob uma estética vaporosa, movimento contrário ao que parece ser a tendência atual do steampunk de língua inglesa, progressivamente mais voltado para a fantasia em suas publicações a partir de 2010.

17 Neste artigo, limitei-me a mapear as publicações em prosa associadas à estética steampunk na França; não estão contempladas, portanto, as produções feitas em outros contextos francófonos, como no Quebec, na Suíça e na Bélgica. Acerca da cena bruxelense steampunk ver o artigo "Hier sera demain: Steam-et Diesel-punk", de Roland Van der Hoeven (2017). 


\subsection{EDITORAS E COLEÇÕES ESPECIALIZADAS}

Na seção anterior, uma editora se destacou por ter sido a responsável pela maior parte das primeiras publicações relativas ao steampunk em França. Barillier e Colson comentam nesse sentido que as "origens do steampunk francês estão fortemente ligadas à história de uma editora então nova: Mnémos, que, em alguns volumes, lança vários jovens autores, em sua maioria originários do mundo dos RPGs, onde já tinham dado seus primeiros passos” (2014, p.146 - tradução nossa). Criada em 1996 por Stéphane Marsan e Frédéric Weil, escritores de RPGs foi a primeira casa da maior parte dos primeiros vaporistes. A editora surgiu, em um primeiro momento, com o objetivo de publicar mais obras de RPGs, no entanto, logo se especializou em autores nacionais de fantasia e ficção científica.

Em 2000, Marsan deixa a direção da empresa e funda a editora Bragelonne, sem dúvida a casa editorial especializada em literaturas do imaginário mais bem-sucedida na França hoje. Bragelonne é responsável por publicar em francês nomes de grande peso de terror, FC e fantasia como Joe Abercrombie, Clive Barker, Terry Brooks, Arthur C. Clarke, Peter V. Brett, Orson Scott Card, Raymond E. Feist, Robert E. Howard, Kim Newman, Andrzej Sapkowski, Patrick Rothfuss dentre tantos outros. Além de também ser a casa de Bernard Cornwell e outros grandes nomes do romance histórico e de outras vertentes de literatura pop, concentrando, portanto, numa única editora o papel que, no Brasil, dividem editoras como Aleph, DarkSide, Intrínseca, Arqueiro e a extinta Saída de Emergência.

No que diz respeito a títulos steampunk, Bragelonne se destaca por ter criado uma coleção dedicada somente ao gênero, em cujas 
capas "retrô" lê-se o nome da estética em garrafais letras douradas, com acabamento em hot stamping. Nessa coleção, títulos franceses importantes como Arcadia e Confissions d'un automate mangeur d'opium foram relançados, ao lado de obras novas, como as de Victor Fleury, de grandes nomes do universo francófono, como Pierre Pével, e de nomes internacionais, tal Mark Gatiss, autor de 0 Ambar do Diabo (embora seja mais conhecido por sua série televisiva Sherlock produzida pela BBC), Emma Jane Holloway, autora de Um estudo em Seda, espécie de pastiche steampunk de Um estudo em Vermelho, de Conan Doyle, a Trilogia Steampunk, de Paul Di Filippo, bem como alguns romances de dois membros do trio fundador do gênero: James P. Blaylock e Tim Powers. A esses, somam-se dois livros críticos de papel fundamental para sua difusão e compreensão: La Bible Steampunk (2014), de Jeff Vandermeer e S. J. Chambers, e Le Manuel Steampunk (2016), de Jeff Vandermeer e Desirina Boskovich, originalmente lançados nos EUA, respectivamente, em 2010 e 2014, obras que ampliam os caminhos para a publicação de mais estudos voltados ao retrofuturismo em França.

La Bible apresenta um panorama bastante aprofundado sobre a origem e as ramificações do steampunk, com especial destaque para suas manifestações em outras mídias e artes, bem como para a moda e o artesanato steampunk. Os autores mencionam também produções de vários países, notadamente do Brasil, dando destaque à pioneira antologia Steampunk: Histórias de um passado extraordinário (Ed. Tarja, 2008), organizada por Gianpaolo Celli, e, particularmente, aos textos de Fábio Fernandes, Romeu Martins e Jacques Barcia (cf. VANDERMEER; CHAMBERS, 2014, p.210-213). No que concerne à França, curiosamente, 
citam apenas dois nomes pouco conhecidos, apesar de terem trabalhos interessantes: Vincent Bénard, autor de Les historiettes de Monsieur Sandalette, mistura de web-comic e fotonovela de publicação independente disponível online, e Sam Van Olffen, gravurista, escultor e ilustrador ${ }^{18}$. Já Le Manuel Steampunk apresenta realmente dicas e instruções para confecção de itens e obras steampunk, desde peças de vestuário e acessórios, até narrativas, apresentando exemplos e modelos, tendo como princípio norteador a ideia do "faça você mesmo" [do it yourself].

Outra editora importante nesse contexto é a Fleuve (até 2013 conhecida como Fleuve Noir), criada em 1949, membro do grande grupo editorial Univers Poche. A Fleuve manteve desde o início o foco na publicação de literatura popular, notadamente romances de espionagem e antecipação, tendo publicado importantes nomes do cenário internacional das literaturas do imaginário em geral, como Robert Jordan e China Miéville. No que concerne à onda steampunk, foi a responsável pela publicação do importante livro L'Équilibre des paradoxes, de Michel Pagel, antes mencionado, dentre outros títulos franceses ou estrangeiros, como $O$ Coração perdido dos autômatos, de Daniel H. Wilson.

Por fim, vale ainda mencionar a editora Les Moutons Éléctriques (em português: "As ovelhas elétricas", título que homenageia a obra de Philip K. Dick), fundada em 2003, por André-François Ruaud e Olivier Davenas, o primeiro deles bastante conhecido por seus ensaios e antologias, sendo várias vezes citado por Girardot

18 A ausência de qualquer um dos nomes elencados ao longo desse ensaio no panorama de Vandermeer e Chambers mostra o precário contato entre a cena anglófona e a francófona, denunciando a falta de traduções de autores franceses para o inglês, salvo possíveis e pontuais exceções. 
e Méreste. A editora é responsável pela publicação de Tout le Strampunk!, de Étienne Barillier e Raphaël Colson, bem como de outros estudos, antologias e de vários romances do gênero, como Les Coeurs Enchainés e Les Ames Envolées, os dois volumes constituintes da série Pax Germanica, de Nicolas Le Breton.

\subsection{ESTUDOS E MANUAIS}

Como já se disse, o steampunk pouco foi estudado no século $X X$ e, mesmo no novo milênio, demora um pouco para chamar a atenção da academia, o que torna tão importante, portanto, a publicação pioneira do artigo de Girardot e Méreste, bem como dos demais artigos do dossiê no qual foi publicado originalmente. Todavia, a bem da verdade, o estudo das Littératures de L'Imaginaire em França, de modo abrangente, é ainda relativamente recente e deriva em grande parte, em um primeiro momento, de esforços de pesquisadores independentes, e em particular de escritores.

Para além dos estudos sobre o fantástico (stricto sensu) oitocentista, bastante consagrados, como os de Pierre-Georges Castex, Tzvetan Todorov, Irène Bessière, Roger Caillois, Louis Vax, Jean-Luc Steinmetz, Jean-Baptiste Baronian ${ }^{19}$, e ocasionais estudos sobre ficção científica e horror ao longo do século XX, como os de

19 Autores respectivamente dos volumes: Le Conte fantastique en France de Nodier à Maupassant (Castex, 1951), Introdução à literatura fantástica (Todorov, 1970), Le Recit Fantastique (Bessière, 1973), Au coeur du fantastique (Caillois, 1965), L'art et la littérature fantastiques (Vax, 1960), La Littérature fantastique (Steinmetz, 1990), Un nouveau fantastique : esquisses sur les métamorphoses d'un genre littéraire (Baronian, 1977) e Panorama de la littérature fantastique de langue française (Baronian, 1978). Além desses, cita-se os trabalhos de Bozetto: L'obscur objet d'un savoir : fantastique et science-fiction, deux littératures de l'imaginaire (1992), Territoires des fantastiques : des romans gothiques aux récits d'horreur moderne (1998), Du fantastique iconique : pour une approche des effets du fantastique en peinture (2001), Le fantastique dans tous ses états (2001), Passages des fantastiques : des imaginaires à l'inimaginable (2005), La science-fiction (2007) e Fantastique et mythologies modernes (2007). 
Roger Bozetto, pouco há antes dos anos 2000 sobre as mais novas vertentes do insólito ficcional, como a fantasia (e suas diversas subcategorias) e o próprio steampunk. Como uma resposta a isso, viu-se dois movimentos.

De um lado, houve uma reação do meio acadêmico no qual pesquisadores oriundos de outras áreas das letras ou de áreas afins - particularmente críticos literários e historiadores medievalistas começaram a se interessar pelos estudos da fantasia, como é o caso de Anne Besson, autora do texto seminal La Fantasy (2007) e diretora do premiado Dictionnaire de la Fantasy (2018), dentre outros volumes, bem como de William Blanc, historiador de formação, autor de diversos livros que fazem a ponte entre a história, a FC e a fantasia contemporâneas, como Le Roi Arthur, un mythe contemporain (2016), Super-héros: une histoire politique (2018) e Winter is coming: une brève histoire politique de la fantasy (2019), para citar apenas os mais célebres. Estes dois pesquisadores, bem como vários outros, começaram a organizar eventos e publicações em torno dessas questões tornando a pesquisa em literaturas do imaginário uma realidade cada vez mais cotidiana.

Atualmente, já é possível encontrar artigos, teses e dissertações francófonos dedicados ao steampunk, dentre os quais, à guia de exemplo, podemos destacar dois trabalhos de notável fôlego e rigor analítico: Peter Pan contre le héros victorien: la poétique du recyclage dans le Cycle de Kraven de Xavier Mauméjean, de Sabrina Riel, dissertação de mestrado defendida em 2015 na Universidade de Montreal, no Canadá, na qual a autora efetua uma leitura bastante profunda da obra de Mauméjean justamente a partir do princípio de reciclagem proposto por Girardot e Méreste; e Dragons à vapeur: 
vers une poétique de la fantasy néo-victorienne contemporaine, tese de doutorado de Caroline Duvezin-Caubet defendida na Université Côte d'Azur em 2017, na qual são discutidas as particularidades do que a autora chama de "fantasias neo-vitorianas", dentre as quais inclui obras steampunk, ucrônicas e alternativas em geral.

De outro lado, houve concomitantemente uma reação de entusiastas, jornalistas e escritores que, vendo uma lacuna nos estudos do imaginário, começaram eles próprios a pesquisar e a publicar livros sobre essas questões, como é o caso de AndréFrançois Ruaud e de seus esforços na difusão da fantasia. Ruaud, além de ter cofundado a editora Les Moutons Électriques, é um notável e profícuo ensaísta com mais de trinta livros lançados, vários deles dedicados ao steampunk e/ou à fantasia e/ou à ficção científica, dos quais se destacam: Cartographie du merveilleux (2001), texto pioneiro citado por Girardot e Méreste; Panorama illustré de la fantasy et du merveilleux (2004); e Science-fiction, une littérature du réel (2006), escrito com Raphaël Colson, dentre outros. No mesmo caminho, também podemos citar Étienne Barillier, responsável, com Arthur Morgan, pelo Guide Steampunk e, com Raphaël Colson, por Tout le Steampunk!, já anteriormente citados, além dos próprios Girardot e Méreste que, embora sejam professorespesquisadores, não são, inicialmente, da área de literatura. Todos esses esforços, somados ainda às publicações dos livros co-escritos por Vandermeer tornaram a pesquisa em steampunk na França e em outros contextos francófonos (como o Quebec, a Bélgica e a Suiça) muito mais viável, e, obviamente, também contribuíram para sua difusão entre leitores e jovens escritores. 


\section{3. ÚLTIMAS CONSIDERAÇÕES}

Diante desse levantamento da literatura steampunk contemporânea francesa, e através do diálogo com o artigo "O Steampunk: uma máquina literária de reciclar o passado", de autoria dos escritores-pesquisadores francês Girardot e Méreste, parece, pois, evidente a importância do steampunk no contexto literário francês, onde se desenvolveu a partir do modelo importado estadunidense, tornando-se algo novo, em diálogo com a própria tradição francesa, em um movimento semelhante ao visto no cenário brasileiro, de maneira que o entender parece nos ajudar na compreensão desse fenômeno literário em nosso próprio país. Sua difusão demandou também o surgimento de nossos estabelecimentos editoriais, como Mnémos, especializados nas novas vertentes das literaturas do imaginário, bem como suscitou a criação de uma crítica literária igualmente especializada e engajada, com consequente publicação de belos volumes e estudos que serviram de base para o desenvolvimento de uma crítica acadêmica, no seio das universidades, onde, como se mostrou, o trabalho apenas começou.

Paralelamente, o presente ensaio espera ter mostrado a importância desse texto pioneiro importante aos estudos do steampunk não apenas em contextos francófonos, mas também para as pesquisas realizadas por pesquisadores brasileiros, e, sobretudo, ter mostrado a relevância do conceito estrutural e estruturante da reciclagem, a partir do qual o gênero e, depois, a estética steampunk se organizou e vem se desenvolvendo, para além de suas limitações iniciais, seja no concernente ao 
suporte, seja no concernente às restrições geográficas. Espera-se ainda ter mostrado como o steampunk se transformou ao longo de seus mais de quarenta anos de existência, ganhando novas mídias e novos espaços, nos quais adquiriu contornos próprios e características novas, sem nunca, contudo, perder sua essência, demandando questionamentos epistémicos para se entender seu lugar na contemporaneidade, uma vez que oscila entre diferentes categorizações, ora como gênero autônomo, ora como movimento artístico, ora como subcategoria afiliada à FC, ora ainda como estética capaz de se desdobrar em diferentes tipos de produtos culturais e artísticos, que, felizmente, não para de se desenvolver e se transformar.

\section{REFERÊNCIAS}

ARGÜELLES, M. (Dir.) (2013). Steampunk Cinema: un repaso a las 25 mejores películas steampunk de la historia. Madri: Tyrannosaurus Books.

BARILLIER, Étienne; MORGAN, Arthur (2013). Le Guide Steampunk. Chambéry, França: Actusf.

(2014). Tout le Steampunk! Montélimar, França: Les Moutons Électriques

Éditeur.

CALEGARI, Lizandro Carlos; AMARAL-OLIVEIRA, Anderson (2018). "Um personagem, dois mundos: Isaías Caminha em 1909 e em 2014". Revista Abusões, (7), Rio de Janeiro, 230-252. In https:// www.e-publicacoes.uerj.br/index.php/abusoes/article/view/ 34215/27388 Acesso em Jan.2020.

CHAVES, Jayme S. (2015). Viagens Extraordinárias e ucronias ficcionais: uma possível arqueologia do steampunk na literatura. (Dissertação - Mestrado) Rio de Janeiro: UERJ.

(2019). "Ficção científica retrofuturista e fantasismo brasileiro". Revue Études Romanes de Brno, 40(2), 101-119. 
COSTA, Joana G. (2013). Steampunk: utopismo e neovitorianismo nos séculos XX e XXI. (Dissertação - Mestrado). Universidade Nova de Lisboa: Lisboa.

DUVEZIN-CAUBET, Caroline (2017). Dragons à vapeur: vers une poétique de la fantasy néo-victorienne contemporaine. (Tese - Doutorado). Université Côte d'Azur: Nice.

(2006). "Le steampunk: une machine littéraire à recycler le passé". Revue Cycnos, 22(1), Nice, 1-11. In http://revel.unice.fr/cycnos/index.html?id=472 Acesso em Jan.2020.

GIRARDOT, Jean-Jacques; MÉRESTE, Fabrice (2020). "O steampunk: uma máquina literária de reciclar o passado". Bruno A. Matangrano (Trad. e Notas). Revista Abusões, v.11(11), Rio de Janeiro.

LUIZ, Lucio (2008). "Fan Fictions de Super-heróis das HQs: Intertextualidade e Pastiche". Anais do XXXI Congresso Brasileiro de Ciências da Comunicação da Intercom, Sociedade Brasileira de Estudos Interdisciplinares da Comunicação, Natal, RN, 2 a 6 de setembro, p.1-9.

MATANGRANO, Bruno. A. (2016a). "A Hora do 'Steampunk'”. Caderno Cultura. Jornal O Extra, 1(6), Fernandópolis, São Paulo, 4.Jun., p.C2.

(2016b). "O olhar contemporâneo na releitura do moderno: A lição de anatomia do temível Dr. Louison". Revista Estudos de Literatura Brasileira Contemporânea, (48), Brasília, 247-280. In https://goo.gl/kY2PwJ Acesso em Jan.2020. MATANGRANO, Bruno A.; TAVARES, Enéias (2018). Fantástico Brasileiro: o insólito literário do romantismo ao fantasismo. Curitiba: Arte \& Letra.

MOISÉS, Massaud (2004). Dicionário de termos literários. São Paulo: Cultrix.

PEGORARO, Éverly (2012a). "Os steampunks e a cultura da mídia: apropriações de uma proposta retrofuturista no cenário brasileiro". Revista Mediaciones Sociales, Madri, II, 72-94. In http://goo.gl/BKjuva Acesso em Jan.2020.

(2012b). "Steampunk: as transgressões temporais negociadas de uma cultura retrofuturista". Cadernos de Comunicação, Santa Maria, 16, 389-400. In http://goo.gl/CnqMmf Acesso em Jan.2020.

(2014). "Retrofuturismo e visualidade steampunk no Brasil". Revista Latinoamericana de Ciencias de la Comunicación, 11, 88-96. In http://goo.gl/ coOrae. Acesso em Jan.2020. 
(2015). No compasso do tempo steampunk: o retrofuturismo no contexto brasileiro. Jundiaí, SP: Paco Editorial.

RIEL, Sabrina (2015). Peter Pan contre le héros victorien: la poétique du recyclage dans le Cycle de Kraven de Xavier Mauméjean. (Dissertação - Mestrado). Université de Montréal: Montréal.

SANT'ANNA, Affonso R. de (2007). Paródia, paráfrase \& cia. São Paulo: Ática.

TAVARES, Enéias (2017). “Polifonia retrofuturista: a (re)criação de vozes literárias na série Brasiliana Steampunk". Revista Scriptorium, 3(1), Porto Alegre, 42-57. In revistaseletronicas. pucrs.br/ojs/index.php/scriptorium/article/view/27991/0 Acesso em Jan.2020.

; MATANGRANO, Bruno A. (2016). "A Humanização do monstro no seriado televisivo Penny Dreadful". Revista Abusões, (2), Rio de Janeiro, 181-219. In https://goo.gl/DGGOXN Acesso em Jan.2020.

(2018). "Educação e (de)formação do gênero feminino na série Penny Dreadful". Revista Todas as Musas, 9(2). São Paulo, 143-159. In https://www.todasasmusas.com.br/18Eneias_Farias.pdf Acesso em Jan.2020.

VAN DER HOEVEN, Roland (2017). "Hier sera demain: Steam-et Diesel-punk à Bruxelles”. Cahiers Bruxellois, XLIX(1), 437-456.In https://www.cairn.info/revuecahiers-bruxellois-2017-1-page-437.htm Acesso em Jan.2020.

VANDERMEER, Jeff; CHAMBERS, S. J. (2014). La Bible Steampunk. C. Carrière, A. Demaegd e M.-A (Trad. francesa). Matignon. Paris: Bragelonne. 